\title{
Appreciating Support - Antecedents of Subscription-Based Crowdfunding Campaign Success
}

\author{
Hendrik Jöntgen \\ Goethe University Frankfurt \\ joentgen@wiwi.uni-frankfurt.de
}

\begin{abstract}
Using subscription-based crowdfunding platforms, content creators can transform their social embeddedness from social media websites into financial support and subsequently gain independence from advertisers. This study examines the antecedents of campaign success for subscription-based crowdfunding campaigns and how content creators can use them to run successful campaigns. For this, we crawled a comprehensive data set from the largest and most universally used subscription-based crowdfunding platform Patreon. Our results show that campaign creators should write an extensive campaign description, offer multiple reward levels with a wide span of costs, lividly engage with their community while focusing on postings with a high level of media richness, and use their social media followers to bring their campaign to success. We contribute to previous research by evaluating the effects of crowdfunding campaign characteristics that previous research only hypothesized and by focusing on the novel concept of subscription-based crowdfunding.
\end{abstract}

\section{Introduction}

While the embeddedness of economic transactions in social relationships is an old concept $[1,2]$, the creation, maintenance, and observation of social embeddedness have become significantly more manageable through the use of social media platforms $[3,4,5]$. By using crowdfunding platforms, especially subscription-based ones, content creators can use their social embeddedness to transform their social media followers or, respectively, content followers into financial supporters. Therefore, these platforms facilitate empowerment for content creators by providing them with independence from ad revenue and promotions. Therefore they can provide their content on their own accord without the need to cater to any regulations or black-box algorithms like YouTube's recommendation system [6]. Especially in times of crisis and financial uncertainty, crowdfunding platforms offer a valuable service to content creators, as can be seen by the rising number of Patreon campaigns amongst the Covid-19 pandemic in 2020 [7].

Even though the topic of crowdfunding platforms, as well as supporters' motivation to contribute to their campaigns, has already been the focus of research in the IS community $[8,9,10,11]$, subscription-based crowdfunding (SBC), which differs in many substantial aspects from time-limited crowdfunding, has not received widespread coverage in IS research hitherto. SBC differs from time-limited crowdfunding by supporters providing recurring payments over an open-ended period instead of a one-time payment during a fixed period [12]. Also, SBC campaigns offer recurring rewards and are more focused on the campaign creator themself instead of on a single project. Because of these differences, it is to be assumed that individuals' motivation to support SBC campaigns differ in a similar fashion from their motivation to support time-fixed crowdfunding campaigns. Although SBC started to receive some attention in recent years $[12,13,14]$, the antecedents of successful SBC campaigns, particularly with regard to their differences from time-limited crowdfunding, remain in large parts unknown. Therefore, this paper aims to answer the following question:

RQ: Which subscription-based crowdfunding campaign characteristics lead to a successful campaign?

To answer this research question, we programmed two web crawlers to gather the data about every crowdfunding campaign on Patreon $(\mathrm{N}=161,214)$ and analyze the resulting data using multiple regression models. Furthermore, this paper offers an overview of previous research on crowdfunding and especially subscription-based crowdfunding, which we then use to formulate our hypotheses and create our research model. Then, we describe the crawling process as well as the crawled data and the statistical methods used to analyze 
them. Finally, we analyze our results and discuss them alongside our study's limitations and potential future research.

We add to the previous research by focusing on SBC instead of time-limited crowdfunding and analyzing novel campaign characteristics, like the price span of reward levels offered or the span of goal amounts which is unique for SBC campaigns and whose effects have only been theorized before. Another addition to the previous research is our dedicated analyses of SBC campaigns' social media connection and creators' activity on their campaign through several different posting types. We do this by analyzing real campaigns from a novel, up-to-date and comprehensive data set.

Our study shows that creators of SBC campaigns should offer an extensive description of their campaigns. By offering multiple reward levels with a wide price span, they can skim the different degrees of willingness to pay off their supporters. On a similar note, campaign creators should actively interact with their community, whereas they should prefer postings with high media richness. Finally, campaign creators should link multiple social media websites to their campaign, whereby we found that the usage of Instagram, Facebook, and Twitch has the biggest positive influence on campaign success.

\section{Related Research}

\subsection{Crowdfunding}

Crowdfunding platforms offer campaign creators the opportunity to realize their social or commercial campaign by accepting money from a network of individuals (also called supporters) in return for varying types of rewards $[15,16]$. While many different types of crowdfunding platforms exist, this paper's predominant distinction is between "time-limited" crowdfunding and subscription-based crowdfunding (as explained below).

2.1.1. Time-limited Crowdfunding. Most of the time, crowdfunding campaigns are time-limited to a fixed deadline in which the previously set campaign goal has to be reached for the campaign to be successful [17]. We call this kind of crowdfunding "time-limited crowdfunding". Depending on the used crowdfunding model, payments are processed only for successful campaigns ("all-or-nothing") or for all campaigns ("all-or-more") [18]. Several campaigns offer varying types of rewards for their supporters (reward-based crowdfunding) or even no rewards at all (charity-based crowdfunding) [19, 9, 10]. Another commonly used distinction of crowdfunding platforms is based on the type of rewards for the supporters. Here, researchers differentiate between lending-based and equity-based crowdfunding platforms $[20,21,22,10,23,24,25]$.

\subsubsection{Subscription-Based Crowdfunding.}

Besides the just described form of crowdfunding, there also exists the so-called subscription-based crowdfunding where content creators can connect with their fans and receive financial support in exchange for their content and optional additional rewards like exclusive virtual content or physical rewards [14]. By using SBC platforms, creators are becoming financially independent and no longer need to rely on ad revenues or promotions. In comparison to time-limited crowdfunding, SBC differs in several aspects:

Supporters of SBC campaigns provide recurring payments instead of one-time payments and can stop those payments at any time if they wish so [12]. SBC campaigns neither have a fixed end time nor strict campaign goals [17]. Supporters can join at any time, and their payments get processed, whether a specific campaign goal is reached or not [12]. Instead of realizing a single product, SBC campaigns are most of the time focusing on the continuous content of one or multiple content creators.

SBC only emerged recently and gained popularity by platforms like Patreon or OnlyFans. Parallel to the rise in popularity of these platforms, the topic of SBC is also gaining popularity in IS research. In his analysis of leaked data from Patreon, Regner (2020) analyzed individual pledge data to campaigns and their descriptions to examine determinants of campaign success and identified the option to cancel one's pledge at any time as a feedback mechanism to the campaign's creator [12]. Researchers could also show that running an SBC increases the popularity of content creators' YouTube channels and goes hand in hand with a higher frequency of video uploads $[13,14]$.

\subsection{Motivation for Supporting Crowdfunding Campaigns}

Analogous to the diversity of different crowdfunding campaigns, the motivations of their support are also manifold. To understand supporters' motivation to support crowdfunding campaigns, we are using self-determination theory [26]. Broadly speaking, supporters of crowdfunding campaigns can be both intrinsically and extrinsically motivated [27, 19, 28].

Extrinsic motivation is driven by the expectation of external rewards. Especially in the context of reward-based crowdfunding, the motivation by a utilitarian or financial gain is predominant [29]. 
Ryu and Kim (2016) identified "interest, playfulness, philanthropy, reward, relationship and recognition" as motivators for supporting crowdfunding campaigns [30]. Supporters want to help others, receive awards and recognition, and participate in a community [8, 18]. Reward-based crowdfunding campaigns offer their supporters tangible compensations like offering the crowdfunded product at a reduced price, with additional perks, or with credits to the supporters [23, 24]. For equity-based crowdfunding, these rewards can appear in the form of equity stakes or similar benefits in the crowdfunded enterprise [21, 10, 24], and in lending-based crowdfunding campaigns, supporters can expect interest rates on their money paid $[31,24]$.

In contrast, intrinsic motivation is not driven by such rewards, but by the act of supporting itself. It is interconnected with altruism and is a major driver for behavior that benefits others [29, 28] and thus for supporting donation-based crowdfunding campaigns $[9,10]$. Especially in subscription-based crowdfunding campaigns, individuals identify themselves as being part of a community and are thus willing to help [32].

Due to the differences between subscription-based and time-limited crowdfunding campaigns, individuals' motivation to support them are likely to differ as well and are thus subject for this research.

Those on the receiving end of crowdfunding campaigns, their creators, are also motivated by varying factors. According to Gerber and Hui (2013), crowdfunding campaign creators are motivated by "the desire to raise funds, expand awareness of work, connect with others, gain approval, maintain control, and learn" [18].

\section{Patreon}

Patreon is a subscription-based crowdfunding platform where creators of varying kinds of content (e.g., videos, podcasts, music, and others) and individuals who consume it meet each other. Like other crowdfunding websites, users on Patreon can create crowdfunding campaigns with varying reward levels and multiple goals and receive money for their campaign directly from their fans (also called "patrons"). We display an example of such a campaign in Figure 1.

On Patreon, campaign creators (1) can offer multiple membership levels (2) each with different costs (3) and rewards (4) (also called "reward levels"). In addition to these campaign characteristics, campaign creators are also able to write a description for their campaign in which they introduce themselves, describe their campaigns as well as what potential supporters can

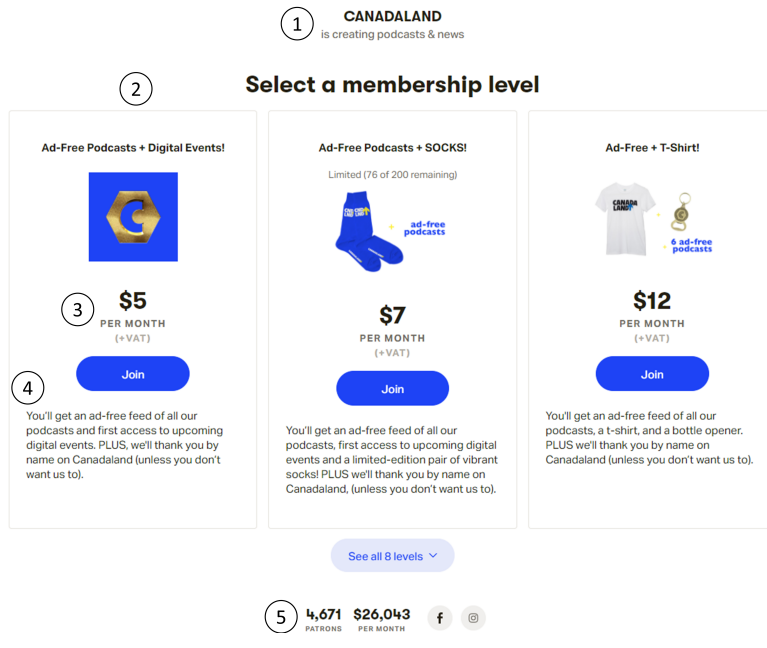

Figure 1. Exemplary Campaign on Patreon (Screenshot).

expect when supporting the campaign. Users can also create certain goals that get unlocked when a specific income or a specific number of supporters (5) is reached. The payments can occur on a regular basis (e.g., once per month) or on a per-work basis, and thus, we classify Patreon as a subscription-based crowdfunding platform.

Patreon was founded in May 2013 and quickly gained widespread attention. At the beginning of 2016, the platform already provided roughly $\$ 5,000,000$ per month to content creators. In 2020 the number of creators has risen to 180,000 , with 9 million users supporting them financially [33]. In September 2020, Patreon announced that the platform will process over $\$ 1$ billion to content creators per year and has already processed over $\$ 2$ billion since its funding [34].

\section{Research Model}

In order to build the research model, we base our hypotheses on the existing research of time-limited crowdfunding and the motivation to support crowdfunding campaigns in general. We focus on campaign characteristics that can be altered by the campaign creator and on campaign characteristics which, while similar to those from time-limited crowdfunding, could have a different effect on the supporters of these campaigns due to the differences between the two crowdfunding types, and are thus necessary to examine.

The most basic and obvious characteristic of a crowdfunding campaign is its description. The creator of the campaign can describe, promote, and explain to potential supporters what to expect from the campaign. For time-limited crowdfunding, previous research could 
already show that the length of the campaign description has a positive effect on individuals decision to invest in that campaign [35] and thus leads to successful campaigns [36, 37] and even to overfunding [38]. However, in their analysis of a German crowdfunding platform, Kunz et al. (2016) could not find a significant effect for description length on campaign success [39]. Since the focus of subscription-based crowdfunding campaigns is more on the content creator themself and not on a single product or project, the description of subscription-based crowdfunding campaigns is used to describe the reasoning behind the crowdfunding campaign as well as what to expect from it over its indefinite run-time. Thus, it caters to both the intrinsic and extrinsic motivation of potential supporters and we hypothesize:

H1: The length of the description of an $S B C$ campaign has a positive effect on its success.

As described before, extrinsic motivated supporters of crowdfunding campaigns do so to receive rewards $[10,23,24]$. When multiple rewards are available, supporters of crowdfunding campaigns tend to choose the one in the middle [40]. Since potential supporters are heterogeneous and possess different product evaluations and willingness to pay, offering a span of products, each with a different price, will increase the overall support a crowdfunding campaign receives, as $\mathrm{Hu}$ et al. (2015) could show in their theoretical analysis [23]. In the context of time-limited crowdfunding, Koch (2016) could show that the number of offered reward levels positively affects a campaign's overfunding [38]. Furthermore, while Kunz et al. (2017) could not find a significant effect of the number of rewards on a campaign's success [36], Xiao et al. (2014) found a significant negative effect of the number of rewards levels on campaign performance [37] and Kunz et al. (2016) a significant positive one [39]. Because of these inconsistencies in previous research, we decided to examine the effect of the number of rewards again in the context of SBC campaigns:

H2a: The number of reward levels offered by an SBC campaign has a positive effect on its success.

In addition, we also want to examine the previous theoretical considerations by analyzing the data of real SBC campaigns. Following $\mathrm{Hu}$ et al. (2015), we argue that offering a high number of reward levels with varying prices [23] and thus rewards with a high price span has a positive effect on the campaigns overall recurring income. Therefore, we hypothesize:

$\boldsymbol{H} 2 \boldsymbol{b}$ : The price span of the rewards offered by an SBC campaign has a positive effect on its success.

Supporters of crowdfunding campaigns do so to "help to realize ideas" [19]. In the context of SBC campaigns, creators set their goals so their fulfillment can allow them a higher content output or better equipment [14]. Thus, the fulfillment of campaign goals relates to the realization of ideas mentioned by Bagheri et al. (2019). Like rats in a maze which "run faster as they near the food box than at the beginning of the path" [41], campaigns creator are also more likely to increase their attempts to reach a goal if the campaign is close to reaching it [42, 43, 44]. In time-limited crowdfunding, even after reaching a goal, the supporters may still decide to join the campaign, resulting in "overfunding", which is positively affected by a low campaign goal [38]. Since SBC campaigns do not have a single goal to reach but can offer multiple goals, the concept of overfunding does not really apply to them. In subscription-based crowdfunding campaigns, these goals often represent an amount of income with which the creators can create their content independently or in a better way than before and thus those goals cater to both the intrinsic and extrinsic motivations of crowdfunding supporters. Previous research could show the significance of offering a high number of goals for SBC campaigns to positively impact its success [12]. We extend this research not only by our more comprehensive and up-to-date data set but also by examining the span of the goal amounts offered by a campaign. This measure is an indicator of campaigns offering goals with larger spacing from each other regarding the income needed. By offering multiple goals with larger spacing from each other, campaigns can consistently benefit from the previously described effects of goal proximity, and therefore we propose the following two hypotheses:

H3a: The number of goals offered by an SBC campaign has a positive effect on its success.

H3b: The span of the goal amounts offered by an SBC campaign has a positive effect on its success.

In addition to the design of a campaign's reward levels and goals, the campaign's creators' communication with their supporters is another crucial factor for crowdfunding campaigns' success. Livid communication on the part of the campaign creator has a positive effect on campaign success [39, 36, 37] and increases the likelihood of campaign overfunding [38]. In the context of a Chinese crowdfunding platform $\mathrm{Bi}$ et al. (2017) could show that the number of videos on a given campaign acts as a signal of campaign quality and has a positive effect on individuals' decision to invest [35]. However, in SBC campaigns, not all of the posted content from the campaign's creator is visible for individuals currently not supporting the campaign. The creator can decide which posts are visible only for supporters and which posts are visible for everybody. 
According to this, the number of posts of a campaign can not only be an indication for the communication to potential supporters but also shows the sum of unlockable content of a creator and thus caters to the extrinsic motivation of crowdfunding supporters to receive rewards. Either way, we argue that the number of postings has a positive effect on campaign success, whereby we can distinguish between several types of postings (e.g., images, videos, live streams, and others). This argumentation leads us to the following hypothesis:

H4: The number of posts offered by an SBC campaign has a positive effect on its success.

When using SBC platforms, content creators are transforming their followers from social media websites into financial supporters. Crowdfunding campaign creators do not only need to speak to potential supporters' intrinsic and extrinsic motivations, but must first of all reach these potential supporters. In line with this argumentation and based on data from the time-limited crowdfunding platform Kickstarter, Kunz et al. (2017) could show the significant positive effect of Facebook friends and the availability of an external website on campaign success [36]. Subscription-based crowdfunding campaigns are usually focused around a content creator with the goal of financing their content by their social media followers and thus subscription-based crowdfunding campaigns are heavily intertwined with social media platforms. Creators of SBC campaigns are not limited to only using Facebook and can connect several different social media websites to their campaigns. We argue that having a broad social media presence increases the likelihood of transforming followers into financial supporters and thus hypothesize:

H5: The number of social media websites used by an SBC campaign has a positive effect on its success.

Furthermore, we also examine the specific effects of different social media websites. Here, we differentiate between the effects of using Instagram, Facebook, Twitch, Twitter, and YouTube, which were the most commonly found social media website.

Additionally, we also added the number of supporters of a campaign, the number of days since its launch as well as its type as control variables to our model. We display the resulting research model in Figure 2.

\section{Data \& Methods}

To answer both our research questions and to test our hypotheses, we decided to analyze crowdfunding campaigns and their characteristics on the platform Patreon. We decided to analyze campaigns on Patreon

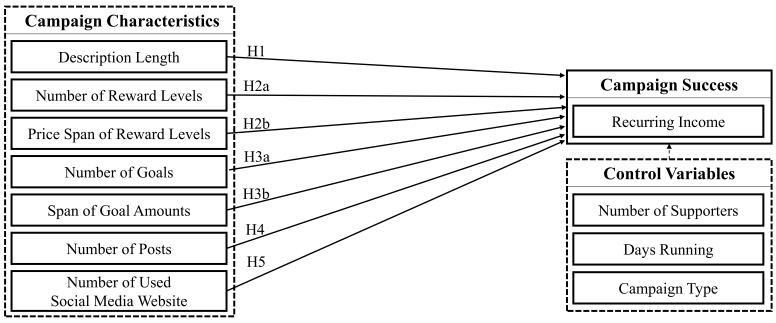

Figure 2. Research Model.

Table 1. Descriptive Statistics of Graphtreon Data $(\mathrm{N}=171,132)$.

\begin{tabular}{|l|l|l|l|l|}
\hline Variable & Mean & Std. & Min & Max \\
\hline Supporters & 50.917 & 347.782 & 1 & 40,399 \\
\hline Recurring Income (in Dollar) & 167.841 & 1127.740 & 0.36 & 158,565 \\
\hline Income Per Supporter & 6.648 & 9.958 & 0.32 & 920.700 \\
\hline Days Running & 703.678 & 549.634 & 0 & 3,245 \\
\hline
\end{tabular}

as an exemplary subscription-based crowdfunding platform since it is the largest and the most universally used subscription-based crowdfunding platform. Other comparable subscription-based crowdfunding platforms are limited to specific content (e.g., OnlyFans) or much smaller than Patreon (e.g., Liberapay) regarding their number of users and payments processed.

\subsection{Graphtreon Data}

Patreon itself only offers minimal data about its platform and crowdfunding campaigns on it. In order to learn about a campaign's existence, potential supporters have to explicitly search for it on the platform or follow a link. Therefore, in order to enable us to crawl the platform systematically, we implemented a workaround by using the third-party website Graphtreon [45].

Graphtreon uses daily crawls of Patreon to offer an overview of its campaigns, their supporters, their recurring income as well as the campaigns' runtime. As the first step of our data collection process, we crawled all Graphtreon data in August 2020 with a web crawler. This led to 171,132 crawled Patreon campaigns. We give a descriptive overview of this data in Table 1.

According to Graphtreon, the average Patreon campaign is running for two years, supported by roughly 51 supporters, which each spend $\$ 6.65$ on average. Also, the average campaign earns $\$ 167,84$. Regarding the hiding of the information about its recurring income, the data shows that $34.18 \%$ of all campaigns $(58,489$ out of 171,132$)$ chose to hide their current recurring income. The data also shows that the most prominent campaign types of Patreon are those creating videos $(26.98 \%)$, followed by "other" content $(10.79 \%)$, podcasts $(7.68 \%)$, music $(7.41 \%)$, games $(7.05 \%)$, writing $(6.05 \%)$ and drawings (5.03\%). Other campaign 
types include comics, animations, photography, cosplay, and magazines, as well as "adult" versions of all these listed campaign types.

\subsection{Patreon Data}

As the second step of our data collection process, we iterated through the crawled campaigns gathered from Graphtreon and visited the corresponding campaign page on Patreon to download further information about each campaign. Following this process, we crawled 161,214 crowdfunding campaigns. The discrepancy of crawled campaigns between our crawled Graphtreon data and this Patreon data (9,918 campaigns) is due to deleted campaigns that were listed on Graphtreon but could not be accessed any longer by our crawler.

Afterwards, our data did not only contain information about the campaigns name, its number of supporters, its recurring income (if not hidden), and its runtime, but also information about the offered reward levels and their characteristics, the defined goals and their characteristics, the social media website used by the creator as well as the past activity of the project in the form of posted texts, images, videos, polls, and other.

In addition to these variables, we also included further variables based on the existing ones. These include the number of goals, the number of reward levels, their average, minimal and maximal cost, as well as the range between each campaign's different reward levels' costs. We also divided the number of posts of each campaign by the campaign runtime to examine the crawled campaigns' average activity. Finally, we investigated the different social media sites connected to a given Patreon campaign. We created additional variables indicating whether or not a given campaign uses Youtube, Twitch, Facebook, Instagram, or Twitter. We also had to remove some outliers in our data consisting of campaigns offering goals or reward levels that are exorbitantly high and not reachable. In total, we removed 2,734 outliers from our data set. We give an overview of the resulting data in Table 5 in the Appendix.

Regarding campaign activity, the average campaign posted roughly 103 posts whereby the mean number of postings of images (75.04) and updates (10.88) were the highest, being followed by videos (8.02), audios (4.49), links (3.29), polls (1.45) and finally live streams (0.23). On the reward levels' design, each campaign offers on average 3.47 reward levels with an average range of $\$ 58,98$ (cost of most expensive reward level - the cost of the cheapest reward level). Concerning creating the goals, the campaigns seem to be more frugal since the average campaign only offers 1.13 goals. Finally, the average campaign has 1.28 social media profiles linked with them, whereby the most popular social media sites are Instagram (37,5\%), Twitter $(32,7 \%)$, and YouTube $(30,5 \%)$, being followed by Facebook $(17,4 \%)$ and Twitch $(9,7 \%)$.

In order to answer our first research question, we decided to use the recurring income of a campaign as our dependent variable as it is a more meaningful indicator of the success of a campaign than the number of supporters since the income per supporter varies widely from campaign to campaign. However, since some creators choose to not display their campaigns' income, we have to exclude them from our data analysis. This limitation of our data is beneficial in an additional way, because campaigns which do not disclose their income also define their goals for a specific number of supporters and not a specific amount of income reached. Thus, by only examining campaigns with their incomes disclosed, we can also examine the effects of campaign goals in a more comparable way.

All noncategorical variables in our analyses are log-transformed, thereby allowing us to identify percentage changes in effect. We deemed this decision to be appropriate primarily because all variables vary widely (as can be seen in Table 5 in the Appendix), so understanding their effects in percentage terms is significantly more useful [46].

\section{Results}

For our model, we ran three different regressions, where we gradually added additional variables. The reasoning behind this is the gradual loss of observations, which comes along with adding these variables. We can only calculate the price span of reward levels and the span of goal amount if a campaign offers at least one reward level or goal, respectively. Thus, for model 1 , we excluded both variables and added the price span of tier levels for model 2, and for model 3 the span of goal amounts as well. We display the results of these three models in Table 2.

We ruled out issues of multicollinearity by obtaining the variance inflation factors (VIFs) associated with each variable (see Table 4 in the Appendix). All VIFs are much lower than 10 , thus eliminating the concern of multicollinearity.

With $\mathrm{R}^{2}$ values between 0.796 and 0.819 , our model can explain most of the variance in the different campaigns' income. Our results show that offering a long description, a high number of reward levels, a high number of total postings, and a high number of used social media websites all have a significant, positive 
Table 2. Regression on Campaigns' Recurring

Income. p-values for each coefficient in brackets.

\begin{tabular}{|c|c|c|c|}
\hline Variable / Model & (1) & (2) & (3) \\
\hline Number of Observations & 104,831 & 93,845 & 51,946 \\
\hline H1: Description Length & $0.053(0.000)$ & $0.037(0.000)$ & $0.034(0.000)$ \\
\hline H2a: Number of Reward Levels & $0.021(0.000)$ & $0.158(0.000)$ & $0.203(0.000)$ \\
\hline H2b: Price Span of Rewards Levels & - & $0.032(0.000)$ & $0.024(0.000)$ \\
\hline H3a: Number of Goals & $0.007(0.000)$ & $-0.001(0.643)$ & $-0.061(0.000)$ \\
\hline H3b: Span of Goal Amounts & - & -4 & $0.005(0.000)$ \\
\hline H4: Total Posts per Day & $0.010(0.000)$ & $0.017(0.000)$ & $0.023(0.000)$ \\
\hline $\begin{array}{l}\text { H5: Number of Used } \\
\text { Social Media Websites }\end{array}$ & $0.019(0.000)$ & $0.016(0.000)$ & $0.021(0.000)$ \\
\hline Number of Supporters & $1.087(0.000)$ & $1.078(0.000)$ & $1.071(0.000)$ \\
\hline Days Running & $-0.122(0.000)$ & $-0.115(0.000)$ & $-0.082(0.000)$ \\
\hline Campaign Type & Yes & Yes & Yes \\
\hline Constant & $1.590(0.000)$ & $1.332(0.000)$ & $1.149(0.000)$ \\
\hline$R^{2}$ & 0.796 & 0.811 & 0.819 \\
\hline
\end{tabular}

effect on the campaign's incomes and its success. Therefore, H1, H2a, H4, and H5 are supported. The price span of reward levels offered also has a significant positive effect, supporting our H2b. Surprisingly, the number of goals offered has a significant positive effect, which gets inverted into a negative one when the variable span of goal amounts gets added into the model. This leads to H3a not being supported, but H3b being supported. Regarding our control variables, the number of supporters has, as expected, the biggest influence on a campaign's income. The campaign type and the number of days a campaign has been running also have significant effects.

We ran two additional models where we split two variables into multiple, more specific ones. For one model, we included the usage of Facebook, Instagram, Twitch, Twitter, and YouTube as dummy variables to our model instead of the total number of used social media websites (Model 4). Parallel to this, instead of including the total number of posts of a campaign, we included the number of audios, images, links, live streams, polls, updates, and videos (Model 5). We display the two resulting additional models in Table 3.

Regarding the usage of social media websites, the results show that while the usage of YouTube does not have a significant effect, the usage of Facebook, Instagram, and Twitch all have a significant positive effect on a campaign's income, and the usage of Twitter has a significant negative one compared to campaigns which do not use these. The different types of posting types, posting images, live streams, and videos, have significant positive effects on the income of campaigns while posting audios and polls have significant negative effects. We could find no significant effects for posting links and updates. We also estimated the effects of these social media connections and different posting types without including the variables price span of reward levels and span of goal amounts, which led to consistent results.
Table 3. Regression on Campaigns' Recurring Income With Social Media Usage and Different Posting Types $(\mathrm{N}=\mathbf{5 3}, \mathbf{7 1 4})$. p-values for each coefficient

\begin{tabular}{|c|c|c|}
\hline \multicolumn{3}{|c|}{ in brackets. } \\
\hline Variable / Model & (4) & (5) \\
\hline Description Length & $0.033(0.000)$ & $0.034(0.000)$ \\
\hline Number of Reward Levels & $0.198(0.000)$ & $0.203(0.000)$ \\
\hline Price Span of Reward Levels & $0.024(0.000)$ & $0.024(0.000)$ \\
\hline Number of Goals & $-0.061(0.000)$ & $-0.058(0.000)$ \\
\hline Span of Goal Amounts & $0.005(0.000)$ & $0.005(0.000)$ \\
\hline Total Posts per Day & $0.023(0.000)$ & - \\
\hline Audios per Day & - & $-0.017(0.007)$ \\
\hline Images per Day & - & $0.029(0.000)$ \\
\hline Links per Day & - & $0.011(0.131)$ \\
\hline Live Streams per Day & - & $0.071(0.004)$ \\
\hline Polls per Day & - & $-0.046(0.000)$ \\
\hline Updates per Day & - & $-0.004(0.454)$ \\
\hline Videos per Day & - & $0.020(0.000)$ \\
\hline $\begin{array}{l}\text { Number of Used } \\
\text { Social Media Websites }\end{array}$ & - & $0.020(0.000)$ \\
\hline Facebook Usage & $0.072(0.000)$ & - \\
\hline Instagram Usage & $0.077(0.000)$ & - \\
\hline Twitch Usage & $0.060(0.000)$ & - \\
\hline Twitter Usage & $-0.012(0.026)$ & - \\
\hline YouTube Usage & $0.018(0.065)$ & - \\
\hline Number of Supporters & $1.080(0.000)$ & $1.081(0.000)$ \\
\hline Days Running & $-0.088(0.000)$ & $-0.085(0.000)$ \\
\hline Campaign Type & Yes & Yes \\
\hline Constant & $0.926(0.000)$ & $1.386(0.000)$ \\
\hline$R^{2}$ & 0.819 & 0.819 \\
\hline
\end{tabular}

\section{Discussion, Conclusion, and Future Research}

Using SBC platforms, content creators can transform their social embeddedness from social media websites to financial support from their social media followers and thus gain independence from advertisers and content recommendation systems (e.g., YouTube's algorithm). In this study, we examined the effects of SBC campaign characteristics on campaign success and, therefore, how campaign creators should design their campaigns in order to be successful. To do this, we crawled SBC campaigns from Patreon, the largest and most diverse SBC platform to date, generated new measures based on their characteristics, and analyzed them.

In line with previous research about time-limited crowdfunding [36, 37] and SBC campaigns [12], our study shows that an extensive campaign description plays an essential role in the success of SBC campaigns. Campaign creators should use the description to promote their campaign and to reduce the uncertainty of their potential supporters. Whereas previous research only examined the effect of the number of reward levels on campaign success $[38,39]$, this study could show that also the range of reward level costs has a significant 
positive effect on campaign success. This effect has only been hypothesized before and can be explained by the fact that campaigns that offer many reward levels with many different costs are more capable of skimming the different levels of willingness to pay off their supporters [23]. Our hypothesis that the number of goals also has a positive effect on campaign success was not supported. However, we could show that the span of goal amounts has a positive effect. The effect of the number of goals becomes negative only after adding the span of goal amounts to the model. Thus, campaign creators should offer a wide span of goal amount, but should not just offer a large amount of goals in order to do so. By doing so, campaign creators can consistently benefit from a high level of goal proximity, leading to increased supporters' attempts to achieve them [42, 43, 44]. In addition, we could also show that livid communication with their supporters is an essential factor for campaign creators to ensure their campaign's success. By looking at different types of postings, we could identify that especially postings with a high level of media richness [47], i.e., live streams, videos, and images, have a positive effect on campaign success. Finally, our analysis could show that including social media website in an SBC campaign leads to campaign success, which reinforces our assumption that through SBC campaigns, content creators can use their social embeddedness to generate financial support.

This study contributes to the existing stream of crowdfunding literature in several ways: Not only do we consider SBC campaigns, which differ significantly from time-limited crowdfunding campaigns and which so far have been underrepresented in previous research, we also enrich the research stream by analyzing the span of reward level costs whose effects were so far only hypothesized and differentiated between different posting types and the usage of different social media websites in our analyses. Our study shows that even though substantial differences between time-limited and subscription-based crowdfunding exist, individuals' motivation to support these campaigns are similar. In addition, we could show that campaign creators need to steadily interact with their community and that they can benefit from their activities on social media platforms. This highlights the benefits of subscription-based crowdfunding for creators that already formed an online community around them and which engage with their community on a regular basis.

Our study also has some limitations. Since we analyzed crawled data from a single point of time, our results are only showing correlation and no causality. Although the relationships investigated are also based on previous literature, and causal relationships could therefore be assumed, our analyses cannot prove these causations. Because of this, future research could enrich our findings by conducting an online experiment or by analyzing SBC campaigns over a duration of time. Another limitation of our data is in the analysis of the used social media websites of campaign creators. Given our Patreon data, we can only observe if campaign creators connected social media sites to their campaigns. Unfortunately, we do not have access to additional information on these social media sites (e.g., number of followers, activity on social media). Future research could include these data to further examine the effect of social media usage on SBC success.

\section{References}

[1] U. Brian, "Embeddedness in the Making of Financial Capital: How Social Relations and Networks Benefit Firms Seeking Financing," American Sociological Review, vol. 64, no. 4, pp. 481-505, 1999.

[2] M. Granovetter, "Economic Action and Social Structure: The Problem of Embeddedness," American Journal of Sociology, vol. 91, no. 3, pp. 481-510, 1985.

[3] G. C. Kane, M. Alavi, G. J. Labianca, P. Stephen, and G. C. Kane, "What's Different About Social Media Networks? A Framework and Research Agenda," MIS Quarterly: Management Information Systems, vol. 38, no. 1, pp. 275-304, 2014.

[4] D. Liu, D. J. Brass, Y. Lu, and D. Chen, "Friendships in Online Peer-to-Peer Lending: Pipes, Prisms, and Relational Herding," MIS Quarterly: Management Information Systems, vol. 39, no. 3, pp. 729-742, 2015.

[5] G. Oestreicher-Singer and A. Sundararajan, "The Visible Hand? Demand Effects of Recommendation Networks in Electronic Markets," Management Science, vol. 58, no. 11, pp. 1963-1981, 2012.

[6] S. Kumar, "The Algorithmic Dance: Youtube's Adpocalypse and the Gatekeeping of Cultural Content on Digital Platforms," Internet Policy Review, vol. 8, no. 2, pp. 1-21, 2019.

[7] S. Perez, "Over 30k Creators Joined Patreon This Month, as COVID-19 Outbreak Spreads - Techcrunch,” 2020. [Last accessed 09-06-2021].

[8] U. Bretschneider and J. M. Leimeister, "Not Just an Ego-Trip: Exploring Backers' Motivation for Funding in Incentive-Based Crowdfunding," Journal of Strategic Information Systems, vol. 26, no. 4, pp. 246-260, 2017.

[9] G. Burtch, A. Ghose, and S. Wattal, "An Empirical Examination of the Antecedents and Consequences of Investment Patterns in Crowdfunded Markets," Information Systems Research, vol. 24, no. 3, pp. 499-519, 2013.

[10] Y. Hong, Y. Hu, and G. Burtch, "Embeddedness, Prosociality, and Social Influence: Evidence From Online Crowdfunding," MIS Quarterly: Management Information Systems, vol. 42, no. 4, pp. 1211-1224, 2018.

[11] H. Zhang and W. Chen, "Backer Motivation in Crowdfunding New Product Ideas: Is It about You or Is It about Me?," Journal of Product Innovation Management, vol. 36, no. 2, pp. 241-262, 2019. 
[12] T. Regner, "Crowdfunding a Monthly Income: An Analysis of the Membership Platform Patreon," Journal of Cultural Economics, 2020.

[13] O. Fan-Osuala, "Impact of Subscription-Based Crowdfunding on Creators' Online Channels: Evidence From YouTube," 25th Americas Conference on Information Systems, AMCIS 2019, pp. 1-5, 2019.

[14] L. Wilson and Y. W. Wu, "Crowdfunding on Patreon by YouTube Sailing Channels," SSRN Electronic Journal, no. 519, pp. 1-18, 2019.

[15] P. Belleflamme, T. Lambert, and A. Schwienbacher, "Crowdfunding: Tapping the Right Crowd," Journal of Business Venturing, vol. 29, no. 5, pp. 585-609, 2014.

[16] J. Paschen, "Choose Wisely: Crowdfunding Through the Stages of the Startup Life Cycle," Business Horizons, vol. 60, no. 2, pp. 179-188, 2017.

[17] V. Kuppuswamy and B. L. Bayus, "Does My Contribution to Your Crowdfunding Project Matter?," Journal of Business Venturing, vol. 32, no. 1, pp. 72-89, 2017.

[18] E. M. Gerber and J. Hui, "Crowdfunding: Motivations and Deterrents for Participation," ACM Transactions on Computer-Human Interaction, vol. 20, no. 6, 2013.

[19] A. Bagheri, H. Chitsazan, and A. Ebrahimi, "Crowdfunding Motivations: A Focus on Donors" Perspectives," Technological Forecasting and Social Change, vol. 146, no. 6, pp. 218-232, 2019.

[20] G. K. Ahlers, D. Cumming, C. Günther, and D. Schweizer, "Signaling in Equity Crowdfunding," Entrepreneurship: Theory and Practice, vol. 39, no. 4, pp. 955-980, 2015.

[21] R. Bapna and A. Umyarov, "Do Your Online Friends Make You Pay? A Randomized Field Experiment on Peer Influence in Online Social Networks," Management Science, vol. 61, no. 8, pp. 1902-1920, 2015.

[22] V. Butticè, C. Franzoni, C. Rossi-Lamastra, and P. Rovelli, "The Road to Crowdfunding Success: A Review of the Extant Literature," Oxford Scholarship Online, no. May 2018, 2018.

[23] M. Hu, X. Li, and M. Shi, "Product and Pricing Decisions in Crowdfunding," Marketing Science, vol. 34, no. 3, pp. 331-345, 2015.

[24] E. Mollick, "The Dynamics of Crowdfunding: An Exploratory Study," Journal of Business Venturing, vol. 29, no. 1, pp. 1-16, 2014.

[25] J. Zhang and P. Liu, "Rational Herding in Microloan Markets," Management Science, vol. 58, no. 5, pp. 892-912, 2012.

[26] E. L. Deci and R. M. Ryan, "The General Causality Orientations Scale: Self-Determination in Personality," Journal of Research in Personality, vol. 19, pp. 109-134, 1985.

[27] T. H. Allison, B. C. Davis, J. C. Short, and J. W. Webb, "Crowdfunding in a Prosocial Microlending Environment: Examining the Role of Intrinsic Versus Extrinsic cues," Entrepreneurship: Theory and Practice, vol. 39, no. 1, 2015.

[28] S. Ryu, J. Park, K. Kim, and Y. G. Kim, "Reward versus Altruistic Motivations in Reward-Based Crowdfunding," International Journal of Electronic Commerce, vol. 24 , no. 2, pp. 159-183, 2020.
[29] M. Cholakova and B. Clarysse, "Does the Possibility to Make Equity Investments in Crowdfunding Projects Crowd Out Reward-Based Investments," Entrepreneurship: Theory and Practice, vol. 39, no. 1, 2015.

[30] S. Ryu and Y. G. Kim, "A typology of crowdfunding sponsors: Birds of a feather flock together?," Electronic Commerce Research and Applications, vol. 16, no. 2, pp. 43-54, 2016.

[31] W. Ke and P. Zhang, "The Effects of Extrinsic Motivations and Satisfaction in Open Source Software Development," Journal of the Association for Information Systems, vol. 11, no. 12, pp. 784-808, 2010 .

[32] K. Ghosh, J. L. Ziegelmayer, and A. P. Ammeter, "Assessing the Impact of Project Founder Reputation and Project Structure on Motivation to Participate in Open Source Software Projects," Proceedings of the Twelfth Americas Conference on Information Systems, AMCIS 2006, vol. 2, pp. 787-791, 2006.

[33] Graphtreon, "Patreon Creators Statistics: Graphs + Analysis." https://graphtreon.com/patreon-stats, 2020. [Last accessed 09-06-2021].

[34] J. Conte, "Create on
Your Cour Terms https://blog.patreon.com/patreon-series-e-announcement, 2020. [Last accessed 09-06-2021].

[35] S. Bi, Z. Liu, and K. Usman, "The Influence of Online Information on Investing Decisions of Reward-Based Crowdfunding," Journal of Business Research, vol. 71, pp. 10-18, 2017.

[36] M. M. Kunz, U. Bretschneider, M. Erler, and J. M. Leimeister, An Empirical Investigation of Signaling in Reward-Based Crowdfunding, vol. 17. Springer US, 2017.

[37] S. Xiao, X. Tan, M. Dong, and J. Qi, "How to design your project in the online crowdfunding market? Evidence from Kickstarter," 35th International Conference on Information Systems "Building a Better World Through Information Systems”, ICIS 2014, pp. 1-8, 2014.

[38] J.-A. Koch, "The Phenomenon of Project Overfunding on Online Crowdfunding Platforms - Analyzing the Drivers of Overfunding," in Twenty-Fourth European Conference on Information Systems, ECIS 2016, 2016.

[39] M. M. Kunz, O. Englisch, J. Beck, and U. Bretschneider, "Sometimes You Win, Sometimes You Learn Success Factors in Reward-Based Crowdfunding," Multikonferenz Wirtschaftsinformatik, MKWI 2016, vol. 1, pp. 467-478, 2016.

[40] A. Simons, M. Weinmann, M. Tietz, and J. vom Brocke, "Which Reward Should I Choose? Preliminary Evidence for the Middle-Option Bias in Reward-Based Crowdfunding," Proceedings of the 50th Hawaii International Conference on System Sciences, HICSS 2017, pp. 4344-4353, 2017.

[41] C. L. Hull, "The Rat's Speed-of-Locomotion Gradient in the Approach to Food.," Journal of Comparative Psychology, vol. 17, no. 3, p. 393, 1934.

[42] J. D. Jensen, A. J. King, and N. Carcioppolo, "Driving Toward a Goal and the Goal-Gradient Hypothesis: The Impact of Goal Proximity on Compliance Rate, Donation Size, and Fatigue," Journal of Applied Social Psychology, vol. 43, no. 9, pp. 1881-1895, 2013. 
[43] R. Kivetz, O. Urminsky, and Y. Zheng, "The Goal-Gradient Hypothesis Resurrected: Purchase Acceleration, Illusionary Goal Progress, and Customer Retention," Journal of Marketing Research, vol. 43, no. 2, pp. 39-58, 2006.

[44] S. Oh and H. Baek, "Successful Crowdfunding: Focusing on Social Interaction and Goal Achievement Motivations," The Journal of Information Systems, vol. 25 , no. 4, pp. 141-161, 2016.

[45] Graphtreon, "Graphtreon: Patreon Earnings + Statistics + Graphs + Rankings." https://graphtreon.com/, 2020. [Last accessed 09-06-2021].

[46] O. N. Keene, "The Log Transformation Is Special," Statistics in Medicine, vol. 14, no. 8, pp. 811-819, 1995.

[47] A. R. Dennis and S. T. Kinney, "Testing Media Richness Theory in the New Media: The Effects of Cues, Feedback, and Task Equivocality," Information Systems Research, vol. 9, no. 3, pp. 256-274, 1998.

\section{Appendix}

Table 4. VIFs of Variables.

\begin{tabular}{|l|c|c|}
\hline Variable & VIF & 1/VIF \\
\hline Description Length & 1.13 & 0.881 \\
\hline No. of Reward Levels & 3.88 & 0.258 \\
\hline Range Reward Level Costs & 3.75 & 0.267 \\
\hline No. of Goals & 5.34 & 0.187 \\
\hline Span of Goal Amount & 5.21 & 0.192 \\
\hline Total Posts per Day & 1.77 & 0.564 \\
\hline No. of Used & 1.21 & 0.829 \\
Social Media Websites & & \\
\hline No. of Supporters & 1.45 & 0.689 \\
\hline Days Running & 1.39 & 0.721 \\
\hline
\end{tabular}

Table 5. Descriptive Statistics of Patreon Data.

\begin{tabular}{|l|l|l|l|l|l|}
\hline Variable & Observations & Mean & Std. Dev. & Min & Max \\
\hline Recurring Income & 104,831 & 157.989 & 934.913 & .36 & 158,565 \\
\hline Description Length & 158,480 & $1,114.56$ & $1,288.969$ & 0 & 81,523 \\
\hline No. of Reward Levels & 158,480 & 3.468 & 2.238 & 0 & 117 \\
\hline Range Reward Level Costs & 144,366 & $5,898.262$ & $14,112.12$ & 0 & 99,902 \\
\hline No. of Goals & 158,480 & 1.128 & 1.745 & 0 & 52 \\
\hline Span of Goal Amount & 54,439 & $67,901.19$ & $143,101.5$ & 0 & 999,400 \\
\hline Total Posts & 158,480 & 103.402 & 395.593 & 0 & 76,024 \\
\hline No. of Audios & 158,480 & 4.487 & 33.782 & 0 & 3,572 \\
\hline No. of Images & 158,480 & 75.039 & 375.068 & 0 & 75,944 \\
\hline No. of Links & 158,480 & 3.294 & 27.862 & 0 & 3,091 \\
\hline No. of Live Streams & 158,480 & .234 & 4.153 & 0 & 603 \\
\hline No. of Polls & 158,480 & 1.449 & 7.710 & 0 & 612 \\
\hline No. of Updates & 158,480 & 10.883 & 52.498 & 0 & 6410 \\
\hline No. of Videos & 158,480 & 8.017 & 57.004 & 0 & 14152 \\
\hline No. of. Used & & & & & \\
Social Media Websites & 158,480 & 1.282 & 1.344 & 0 & 6 \\
\hline Facebook Usage & & & & & \\
\hline Instagram Usage & 158,480 & .174 & - & 0 & 1 \\
\hline Twitch Usage & 158,480 & .375 & - & 0 & 1 \\
\hline Twitter Usage & 158,480 & .097 & - & 0 & 1 \\
\hline YouTube Usage & 158,480 & .327 & - & 0 & 1 \\
\hline No. of Supporters & 158,480 & .305 & - & 0 & 1 \\
\hline Days Running & 158,480 & 51.068 & 341.324 & 1 & 40,399 \\
\hline
\end{tabular}

